\section{Cureus}

\title{
Non-islet Cell Tumor-induced Hypoinsulinemic Hypoglycemia in the Setting of Metastatic Desmoplastic Round Cell Tumor
}

\author{
Nadir Bhuiyan ${ }^{1}$, Purva Sharma ${ }^{1}$ \\ 1. Internal Medicine, University of Miami, Miller School of Medicine, Atlantis, USA \\ $\square$ Corresponding author: Nadir Bhuiyan,nmbhuiyan@med.miami.edu \\ Disclosures can be found in Additional Information at the end of the article
}

\section{Abstract}

A 24-year-old male with metastatic desmoplastic round cell tumor was admitted for fatigue and weakness after chemotherapy. The patient was found to be hypotensive, pancytopenic, and bacteremic. Early treatment with intravenous antibiotics and fluids was efficacious. The hospital course was complicated by recurrent hypoglycemia that was refractory to the standard hypoglycemia protocol. Initial workup revealed low serum insulin and normal C-peptide. Further evaluation revealed elevated IGF-II levels consistent with non-islet cell tumor-induced hypoglycemia. Euglycemia was subsequently achieved with aggressive and continuous infusion of intravenous $10 \%$ dextrose.

Categories: Internal Medicine, Medical Education, Oncology

Keywords: paraneoplastic syndrome, tumor induced hypoglycemia, desmoplastic round cell tumor, non-islet cell tumor induced hypoglycemia

\section{Introduction}

Non-islet cell tumor hypoglycemia (NICTH) is a rare life-threatening paraneoplastic syndrome that can be precipitated by a wide variety of malignancies. In this condition, tumors characteristically secrete detectable hormones, or hormone-like substances that facilitate persistent, rapid declines in blood glucose levels. While there are myriad physiologic pathways that result in tumors causing hypoglycemia, one of the better understood mechanisms is through secretion of insulin-like growth factor II (IGF-II) and its precursor protein. We describe the diagnosis and management of IGF-II mediated of hypoinsulinemic refractory hypoglycemia in the setting of diffuse, metastatic desmoplastic round cell tumor.

Received 05/06/2019

Review began 05/08/2019 Review ended 05/08/2019 Published 05/15/2019

\section{(C) Copyright 2019}

Bhuiyan et al. This is an open access article distributed under the terms of the Creative Commons Attribution License CC-BY 3.0., which permits unrestricted use, distribution, and reproduction in any medium, provided the original author and source are credited.

\section{Case Presentation}

A 24-year-old Hispanic male with recently diagnosed desmoplastic round cell tumor with innumerable metastases, presented with complaints of significant weakness and fatigue after receiving one cycle of vincristine, adriamycin, and ifosfamide (VAI). Eleven days after his first cycle of chemotherapy, he presented to the emergency department with complaints of subjective fever, weakness, and worsening fatigue. He was found to be hypotensive with pancytopenia and was subsequently admitted to the intensive care unit (ICU) for further management. Physical examination was notable for cachexia and rigid hepatomegaly. Both blood cultures were positive for Streptococcus dysgalactiae. CT scan of the abdomen and pelvis with IV contrast revealed impressive metastatic infiltration into the liver (Figure 1). The 


\section{Cureus}

patient's condition rapidly improved with the administration of intravenous fluids and vancomycin. Filgrastim was added to address the neutropenia. On day two of his hospital course, he developed severe hypoglycemia. Initial treatment included boluses of $50 \%$ dextrose solution; after two administrations the patient remained persistently hypoglycemic. Frequent small meals with high sugar content provided negligible benefit. Management was escalated to a continuous infusion of $5 \%$ dextrose solution and ultimately to $10 \%$ dextrose before adequate control of blood glucose was achieved. With no clear cause of hypoglycemia, the tumor was suspected as the etiology. Within 48 hours of intensive correction and monitoring, his blood glucose was stabilized. To differentiate between islet cell tumor-induced hypoglycemia and non-islet cell tumor-induced hypoglycemia (NICTH), the preliminary tests ordered were insulin and C-peptide levels. With a normal C-peptide level and low insulin level, further hormonal causes were explored. Cortisol levels were elevated, likely due to systemic stress response to prior infection and hypoglycemia. Thyroid stimulating hormone (TSH) and thyroxine (T4), were within their normal reference ranges. Growth hormone was elevated (Table 1). The possibility of an auto-immune paraneoplastic process was investigated by searching for insulin antibodies; the results were negative. Insulin-like growth factors I and II (IGF-I, IGF-II) are recognized mediators of NICTH, specifically IGF-II [1]. These polypeptides share structural similarity to pro-insulin revealing, at least in part, the physiologic basis of their effect on serum blood glucose. The ratio of IGF-II to IGF I is used as a diagnostic value in NICTH. A ratio of 10 or greater is the conventional pathognomonic value, 3 is considered the standard baseline [1-4]. IGF-II levels were pointedly elevated in comparison to IGF-I levels, making the ratio indicative of NICTH (Table 1). The patient's blood glucose level was maintained for two weeks but he was not able to tolerate any further chemotherapy. A recurrence of septic shock leads to the development of multi-organ failure. Unfortunately, the patient expired 15 days after admission to the ICU.

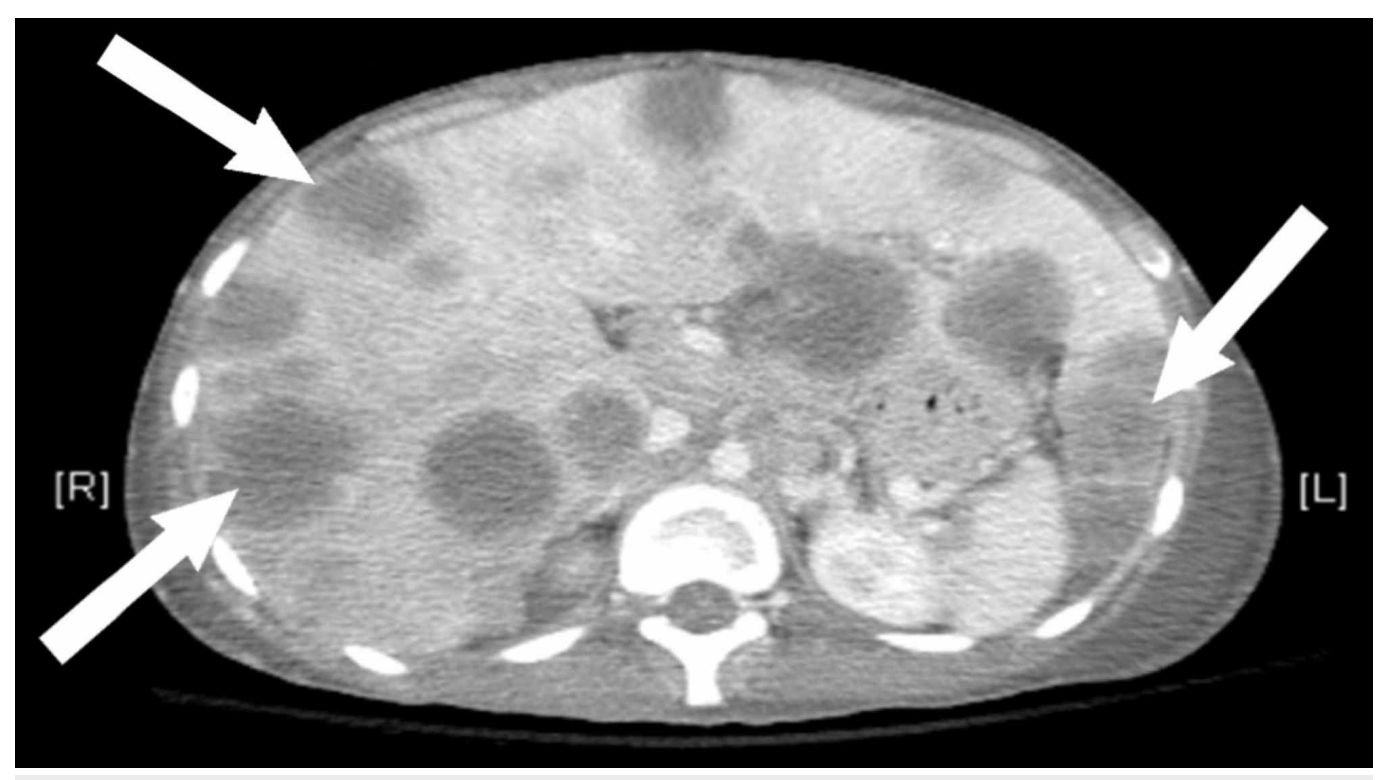

FIGURE 1: Axial CT scan of the abdomen with intravenous contrast demonstrating innumerable liver metastases.

*Arrows demonstrating significant metastatic tumor burden in the liver with massive hepatomegaly. 


\section{Cureus}

\begin{tabular}{|c|c|c|}
\hline Serum Test & Laboratory Value & Reference Ranges \\
\hline Insulin & $1.2 \mathrm{mU} / \mathrm{L}$ & $3-25 \mathrm{mU} / \mathrm{L}$ \\
\hline C-Peptide & $0.61 \mathrm{ng} / \mathrm{mL}$ & $0.48-5.05 \mathrm{ng} / \mathrm{mL}$ \\
\hline Insulin Antibodies & $<5$ & $>$ Or $=5$ is positive \\
\hline Cortisol & $56.63 \mathrm{mcg} / \mathrm{dL}$ & 3.09-16.66 mcg/dL P.M. \\
\hline GH & $16.7 \mathrm{ng} / \mathrm{mL}$ & $0-3 \mathrm{ng} / \mathrm{mL}$ \\
\hline IGF-I & $38.8 \mathrm{mg} / \mathrm{mL}$ & $116-358 \mathrm{ng} / \mathrm{mL}$ \\
\hline IGF-II & 4600 ng/nL & $84-580 \mathrm{ng} / \mathrm{mL}$ \\
\hline |GF-||/| Ratio & 118.6 & Diagnostic at minimal 2/1 ratio \\
\hline
\end{tabular}

\section{TABLE 1: Serum laboratory values.}

GH: Growth hormone; IGF: Insulin-like growth factor.

\section{Discussion}

Tumor-induced hypoglycemia is a serious paraneoplastic syndrome which can be divided into islet cell and non-islet cell sub-types. In regards to the beta ( $\beta$ ) islet cell sub-type, insulinoma is the classic tumor of which $5-10 \%$ are malignant. The non-islet cell sub-type can be further divided into ectopic insulin producing tumors. These include endobronchial carcinoid, cervical squamous-cell carcinoma, neurofibrosarcoma, gastrointestinal stromal tumor (GIST), schwannoma, and paraganglioma [1]. The other division should include a category of insulinindependent hypoglycemia. The vast majority of these tumors secrete circulating factors that have homology with insulin or are insulin secretagogues.

The most frequently reported form of this is IGF-II mediated tumor-associated hypoglycemia. IGF-I and II share protein homology with insulin, capable of activating the receptor and mimicking insulin activity. As one would expect, hypoglycemia is a common consequence of this. Due to over-expression of the IGF-II gene in certain tumors, large quantities of IGF-II and Pro-IGF-II are secreted. Pro-IGF-II is the precursor protein produced by the gene, prior to enzymatic cleavage [4]. In the literature it is often referred to as 'Big IGF-II'. Of note, big IGF-II has more affinity to the insulin receptor, increasing the likelihood that hypoglycemia will manifest. The ratio of IGF-II to IGF-I is used as surrogate measurement for big IGF-II. The physiologic explanation of this is that GH and thus IGF-I are decreased due to negative feedback from high levels of IGF-II. A ratio greater than 10 is considered to be pathognomonic of IGF-II mediated NICTH. The implicated tumors include hepatocellular carcinoma, gastric carcinoma, solitary fibrous pleural tumor of the lung, desmoplastic small round cell tumor, mesothelioma and leiomyosarcoma, among a few others [2-3,5].

Somatostatinomas, typically found in close proximity with the duodenum and within the pancreas, have been implicated as well. These rare neuroendocrine tumors (NETs) excessively secrete somatostatin. The net effect of which impairs gastrointestinal fluid secretion and motility. Thus, a patient's presentation may include abdominal pain, steatorrhea, cholelithiasis, and diabetes mellitus. Glucagon and insulin, among other hormones, can be found at elevated 
levels due to the effects of overabundant somatostatin. Therefore, hypoglycemia in these tumors is not common but may involve suppression of both growth hormone and glucagon. Some NETs may produce glucagon-like peptide 1 (GLP) which results in secretion of insulin from pancreatic B-cells. Other mechanisms of note include antibodies that activate the insulin receptor, increased metabolic demand due to excessive tumor burden, extensive liver infiltration, and metastatic pituitary or adrenal gland invasion resulting in adrenal insufficiency [1].

Management of NICTH involves several methods of glucose correction. After rapid correction of hypoglycemia is achieved with IV dextrose, small and frequent meals should be administered. Ultimately, treatment of the tumor, whether by surgical resection or chemotherapy, should resolve the hypoglycemia. If this is not possible, then continuous infusions of intravenous dextrose may be used. For long-term management using corticosteroids, growth hormone, and glucagon, either individually or in various combinations, is recommended for maintenance of euglycemia $[1-3,5]$.

Desmoplastic small round cell tumor (DSRCT) is soft tissue sarcoma of mesenchymal origin. It presents as a rare aggressive type of cancer, usually affecting young males and located in the abdomen. It presents most often as a multifocal peritoneal malignancy with disseminated abdominal disease. It most commonly involves the omentum and peritoneum followed by the retroperitoneum. It may sometimes involve the kidney as well [6]. Patients may present with abdominal pain, abdominal mass, ascites, or signs of intestinal obstruction. The liver is the most common solid visceral metastatic site. It is also known to have involvement of the thorax including the pleura and lymph nodes. DSRCTs are characterized by chromosomal abnormalities. They present a reciprocal chromosomal translocation, $\mathrm{t}(11 ; 22)(\mathrm{p} 13 ; \mathrm{q} 12)$, that results in fusion of Ewing's sarcoma (EWSR1) and Wilms' tumor (WT1) genes [7]. The fusion protein as a result of this translocation is pathognomonic for DSRCT. Treatment of DSRCT involves a multimodality approach involving chemotherapy, aggressive surgery, tumor debulking, and total abdominal radiation therapy. Overall, the patient response to these treatment modalities is poor and rarely achieves remission. There are only two cases reported in the literature of DSRCT directly manifesting hypoglycemia through big IGF-II [8-10], one in an adult and one in a pediatric patient.

We cannot exclude massive tumor burden or metastatic liver infiltration as a cause of hypoglycemia in our patient. However, we believe that these etiologies are less likely due to the refractory nature of the hypoglycemia in response to intravenous dextrose. This is more consistent with circulation factors that activate the insulin receptor, like big IGF-II.

\section{Conclusions}

This case demonstrates a rare presentation of a paraneoplastic syndrome in a patient with a rare aggressive malignancy. NICTH is caused due to secretion of IGF-II or other related substances. Low levels of insulin or IGF-I in the setting of hypoglycemia should raise suspicion for NICTH. A focused workup including C-peptide levels and ruling out other endocrine causes of hypoglycemia is necessary. The diagnosis is confirmed with an IGF-II:IGF-I ratio greater than 10. Given the rarity of paraneoplastic syndromes there is a paucity of clinical trials to guide management. It is important to be aware of and recognize these syndromes as they can precede or occur at the time of tumor presentation or at a later stage. Continuous infusion of dextrose was successful in treating the hypoglycemia in our patient, however, newer treatment modalities such as anti-IGF-II therapies are being studied and could be an effective option in future.

\section{Additional Information}




\section{Disclosures}

Human subjects: Consent was obtained by all participants in this study. Conflicts of interest: In compliance with the ICMJE uniform disclosure form, all authors declare the following:

Payment/services info: All authors have declared that no financial support was received from any organization for the submitted work. Financial relationships: All authors have declared that they have no financial relationships at present or within the previous three years with any organizations that might have an interest in the submitted work. Other relationships: All authors have declared that there are no other relationships or activities that could appear to have influenced the submitted work.

\section{References}

1. Iglesias P, Díez JJ: Management of endocrine disease: a clinical update on tumor-induced hypoglycemia. Eur J Endocrinol. 2014, 170:147-157. 10.1530/EJE-13-1012

2. Barra WF, Castro G, Hoff AO, Siqueira SA, Hoff PM: Symptomatic hypoglycemia related to inappropriately high IGF-II serum levels in a patient with desmoplastic small round cell tumor. Case Rep Med. 2010, 2010:3. Accessed: May 13, 2019: https:/www.hindawi.com/journals/crim/2010/684045/. 10.1155/2010/684045

3. Zapf J, Futo E, Peter M, Froesch ER: Can "big" insulin-like growth factor II in serum of tumor patients account for the development of extrapancreatic tumor hypoglycemia?. J Clin Invest. 1992, 90:2574-2584. 10.1172/JCI116152

4. Ward CW, Lawrence MC: Landmarks in insulin research. Front Endocrinol (Lausanne). 2011, 2:76. 10.3389/fendo.2011.00076

5. Almaghraby A, Brickman WJ, Goldstein JA, Habiby RL: Refractory hypoglycemia in a pediatric patient with desmoplastic small round cell tumor. J Pediatr Endocrinol Metab. 2018, 31:947950. 10.1515/jpem-2018-0107

6. Wang LL, Perlman EJ, Vujanic GM, et al.: Desmoplastic small round cell tumor of the kidney in childhood. Am J Surg Pathol. 2007, 31:576-584. 10.1097/01.pas.0000213432.14740.14

7. Barnoud R, Sabourin JC, Pasquier D, Ranchère D, Bailly C, Terrier-Lacombe MJ, Pasquier B: Immunohistochemical expression of WT1 by desmoplastic small round cell tumor: a comparative study with other small round cell tumors. Am J Surg Pathol. 2000, 24:830-836.

8. Zhang WD, Li CX, Liu QY, Hu YY, Cao Y, Huang JH: CT, MRI, and FDG-PET/CT imaging findings of abdominopelvic desmoplastic small round cell tumors: correlation with histopathologic findings. Eur J Radiol. 2011, 80:269-273. 10.1016/j.ejrad.2010.06.046

9. Hayes-Jordan A, LaQuaglia MP, Modak S: Management of desmoplastic small round cell tumor. Semin Pediatr Surg. 2016, 25:299-304. 10.1053/j.sempedsurg.2016.09.005

10. Kushner BH, LaQuaglia MP, Wollner N, et al.: Desmoplastic small round-cell tumor: prolonged progression-free survival with aggressive multimodality therapy. J Clin Oncol. 1996, 14:1526-1531. 10.1200/JCO.1996.14.5.1526 